\title{
Ocular Changes in Egyptian Children on Regular Hemodialysis
}

\author{
Somaya Mohamed Abd El-Ghany1, Manal Abd El-Salam1* ${ }^{*}$ Mona Mohamed Farag2, \\ Ola Ali El-Ashwah ${ }^{1}$ \\ ${ }^{1}$ Department of Pediatrics, Faculty of Medicine, Al-Azhar University, Cairo, Egypt \\ ${ }^{2}$ Department of Ophthalmology, Faculty of Medicine, Al-Azhar University, Cairo, Egypt \\ Email: *mana124969@gmail.com
}

How to cite this paper: El-Ghany, S.M.A., El-Salam, M.A., Farag, M.M. and El-Ashwah, O.A. (2019) Ocular Changes in Egyptian Children on Regular Hemodialysis. International Journal of Clinical Medicine, 10, 353-362.

https://doi.org/10.4236/ijcm.2019.106028

Received: April 28, 2019

Accepted: June 25, 2019

Published: June 28, 2019

Copyright $\odot 2019$ by author(s) and Scientific Research Publishing Inc. This work is licensed under the Creative Commons Attribution International License (CC BY 4.0).

http://creativecommons.org/licenses/by/4.0/

(c) (i) Open Access

\begin{abstract}
Background: Chronic Kidney disease (CKD) may cause ocular disorders for many reasons such as uraemia, haemodialysis and hypertension. Aim: To study the ocular changes in a group of Egyptian children with chronic kidney disease on regular hemodialysis. Subjects and Methods: This cross-sectional comparative study was conducted on 30 children on regular hemodialysis and another 30 age and sex-matched healthy children as controls. Their ages ranged from 4 to 17 years. Complete ophthalmological examination including; visual acuity and refraction, anterior segment examination, intraocular pressure (IOP), fundus examination and colored photography were assessed in the same line with routine laboratory investigations for children on regular hemodialysis and their controls. The relation of ocular disorders with related clinical and biochemical variables was measured statistically. Results: The most common eye abnormalities recorded were decreased visual acuity in Lt eye (73.3\%) and Rt eye (60\%), followed by corneal \& conjunctiva calcification were (16.7\%) and (13.3\%) respectively and fundal changes (13.3\%) of the study population. A significant positive relation was found between fundal changes particularly tortuous blood vessel abnormalities with the duration of hemodialysis and serum creatinine level. Conclusion: Ocular abnormalities are common than expected in children on regular hemodialysis. Visual acuity disorder is the major ocular abnormalities recorded in those patients. Regular ophthalmologic assessment is recommended in children to prevent longer-term visual complications.
\end{abstract}

\section{Keywords}

Hemodialysis, Children, Ocular Changes

\section{Introduction}

Although much progress has been made in prevention, detection and treatment, CKD remains a major public health problem [1]. 
In children, early diagnosis and detection of the etiologic factors are important to improve their health outcomes [2].

Patients undergoing chronic hemodialysis (HD) are subject to the unique effects of both uremia and the dialysis procedure on multiple organ systems. Many patients on chronic HD suffer from chronic eye diseases [3].

Chronic kidney disease of any etiology can induce eye disorders secondary to metabolic changes and hemodialysis treatment [4].

Eye changes associated with chronic renal disease include conjunctival erythema, metastatic calcification on the ocular surface, conjunctival degenerations, dry eye, band keratopathy, corneal endothelial impairments, uremic optic neuropathy, pseudotumor cerebri, uremic amaurosis and cataracts [4].

Hemodialysis could influence on visual parameters through changes in blood glucose or possibly other systemic parameters [5].

The aim of this work was to study the ocular changes in a group of Egyptian children with chronic kidney disease on regular hemodialysis.

\section{Subjects and Methods}

This is a cross-sectional comparative study, conducted during the period from May 2016 to January 2017. The study included 60 Egyptian children, 30 children with end stage renal disease (ESRD) (eGFR $\left.<15 \mathrm{~mL} / \mathrm{min} / 1.73 \mathrm{~m}^{2}\right)$ on regular hemodialysis more than 3 months at the time of the study [6]. They were on regular hemodialysis for 4 hours, 3 times weekly, by Fresenius 4008S machine Fresenius Medical Care AG, Bad Homburg, Germany, with polysulfone low flux membrane dialyzer, their ages ranged from (5 - 17) years. Also 30 healthy children with matched age and sex with patients were included as controls. The study population was selected from the nephrology \& hemodialysis unit and the outpatients pediatric clinic of Alzahraa University Hospital. Blood samples were drawn in the morning after an overnight fast of at least $12 \mathrm{~h}$ before the start of the mid-week HD session.

- Children with: Primary eye disorders (acute and chronic), other chronic systemic illnesses that can affect the eye (e.g., rheumatoid arthritis, cystinosis, ...) were excluded from the study. The study patients were subjected to full history (etiology and duration of CKD and dialysis), any ocular manifestations and history of recurrent eye infection, visual affection (visual acuity disorders-dryness-itching-red eye). Informed consent was obtained from the participating parents in adherence to the guidelines of the ethical committee of Alzhraa Hospital, Al-Azhar University, Cairo, Egypt.

- Clinical examination: Meticulous complete general and local systemic examination with special emphasis on manifestations of systemic disease which may affect the eye, and laboratory investigations in the same line with complete ophthalmologic assessment for both patients and their controls.

\subsection{Sampling}

Blood samples were drawn in the morning after an overnight fast of at least $12 \mathrm{~h}$ 
before the start of the mid-week HD session. Five ml were drawn and placed into a plain tube, centrifuged within 30 minutes of collection and serum was separated and divided into:

1) One portion for serum (creatinine, urea, $\mathrm{Ca}, \mathrm{ph}, \mathrm{ALP}$, cholesterol and triglyceride at the same day;

2) Another portion stored at $-20^{\circ} \mathrm{C}$ for until PTH assay.

\subsection{Ophthalmologic Examination}

All enrolled subjects had complete ophthalmic examination, including uncorrected and best corrected visual acuity, intraocular pressure estimation using Goldmann applanation tonometer, anterior segment examination, dilated fundus examination with indirect ophthalmoscope and slit-lamp biomicroscopic examination with +90 non-contact lens. For statistical analysis, visual acuity was converted to logMar fraction (Table 1).

\section{Results}

Table 2 showed significant increase in systolic blood pressure, urea, creatinine, PTH, ALP, cholesterol and triglyceride serum levels in children on hemodialysis

Table 1. LogMar visual acuity conversion chart.

\begin{tabular}{|c|c|}
\hline Snellen acuity & LogMAR acuity \\
\hline $6 / 240$ & 1.6 \\
\hline $6 / 190$ & 1.5 \\
\hline $6 / 150$ & 1.4 \\
\hline $6 / 120$ & 1.3 \\
\hline $6 / 95$ & 1.2 \\
\hline $6 / 75$ & 1.1 \\
\hline $6 / 60$ & 1.0 \\
\hline $6 / 48$ & 0.9 \\
\hline $6 / 38$ & 0.8 \\
\hline $6 / 30$ & 0.7 \\
\hline $6 / 24$ & 0.6 \\
\hline $6 / 19$ & 0.5 \\
\hline $6 / 15$ & 0.4 \\
\hline $6 / 12$ & 0.3 \\
\hline $6 / 9.5$ & 0.2 \\
\hline $6 / 7.5$ & 0.1 \\
\hline $6 / 6$ & 0.0 \\
\hline $6 / 4.8$ & -0.1 \\
\hline $6 / 3.8$ & -0.2 \\
\hline
\end{tabular}

MAR: Minimum Angle Resolutions. 
Table 2. Comparison between patients and control group regarding laboratory data.

\begin{tabular}{|c|c|c|c|c|}
\hline \multirow{2}{*}{ Variable } & \multirow{2}{*}{$\begin{array}{c}\text { Control group } \\
(\text { No. }=30)\end{array}$} & \multirow{2}{*}{$\begin{array}{l}\text { Patients group } \\
\quad(\text { No. }=30) \\
\text { Mean } \pm \text { SD }\end{array}$} & \multicolumn{2}{|c|}{ Independent t-test } \\
\hline & & & $t / X^{*}$ & $P$-value \\
\hline Age (years) & $11.60 \pm 2.24$ & $12.27 \pm 4.10$ & -0.782 & 0.438 \\
\hline \multicolumn{5}{|l|}{ Sex } \\
\hline male & $15(50.0 \%)$ & $18(40.0 \%)$ & $0.606^{*}$ & 0.436 \\
\hline female & $15(50.0 \%)$ & $12(60.0 \%)$ & & \\
\hline Systolic BP (mmHg) & $110.93 \pm 8.75$ & $131.63 \pm 12.59$ & 7.396 & 0.001 \\
\hline Diastolic BP (mmHg) & $71.60 \pm 5.62$ & $84.30 \pm 6.04$ & 8.432 & 0.000 \\
\hline Zscore: weight & $0.27(-0.14-0.79)$ & $-0.77(-1.35-0.65)$ & 2.750 & 0.006 \\
\hline Zscore: height & $0.18(-0.01-0.76)$ & $-0.30(-0.91-0.63)$ & 2.642 & 0.008 \\
\hline Zscore: BMI & $0.37(-0.08-0.71)$ & $-0.53(-1.24-0.52)$ & 2.737 & 0.006 \\
\hline Urea (mg/dl) & $18.43 \pm 3.16$ & $174.56 \pm 46.67$ & -18.280 & 0.001 \\
\hline Creatinine (mg/dl) & $0.57 \pm 0.18$ & $8.10 \pm 2.10$ & -19.583 & 0.001 \\
\hline $\mathrm{Ca}(\mathrm{mg} / \mathrm{dl})$ & $9.66 \pm 0.46$ & $9.69 \pm 2.69$ & 0.060 & 0.952 \\
\hline Phosphate (mg/dl) & $4.34 \pm 0.30$ & $8.21 \pm 3.55$ & 5.431 & 0.001 \\
\hline $\mathrm{PTH}(\mathrm{Pg} / \mathrm{ml})$ & $50.23 \pm 14.38$ & $816.01 \pm 604.28$ & 5.214 & 0.001 \\
\hline $\operatorname{ALP}(\mathrm{U} / \mathrm{L})$ & $187.87 \pm 30.23$ & $418.08 \pm 166.69$ & 6.796 & 0.001 \\
\hline Cholesterol (mg/dl) & $102.48 \pm 11.85$ & $149.40 \pm 35.40$ & 6.884 & 0.001 \\
\hline TG (mg/dl) & $81.52 \pm 19.69$ & $138.44 \pm 60.54$ & 4.897 & 0.001 \\
\hline
\end{tabular}

*: Chi-square test.

compared to their controls with no significant difference regarding serum $\mathrm{Ca}$ level between both groups, but there is a significant decrease in $\mathrm{z}$ score of $(\mathrm{Wt}$, $\mathrm{Ht}$ and BMI) in hemodialysis group compared to their controls.

Table 3 showed that visual abnormalities were detected in 18 children (60\%) in the Rt eye and 22 (73.3\%) in the Lt eye among patients group in comparison to the controls visual abnormalities were detected in 4 of them (13.3\%) in either eye. There was a significant decrease in the degree of visual acuity in children on hemodialysis than their controls.

Table 4 showed that out of 30 patient, 2 patients (6.7\%) had dry eyes symptoms, conjunctiva calcification was detected in 4 patients (13.3\%) and conjunctiva pigmentation in 4 patients $(13.3 \%)$, corneal calcification, in 5 patients (16.7\%), 4 patients (13.3\%) developed fundus abnormalities, 3 patients (10\%) had intra-retinal Hge and only one patient (3.3\%) had myopic fundus.

Figure 1 showed corneal and conjunctival calcification of both eyes in one of the study patients group who examined by Topcon, retinal camera.

Figure 2 showed diffuse retinal hemorrhage in one of the study patients group who examined by Topcon, retinal camera.

Table 5 showed a significant relation between duration of hemodialysis, serum creatinine level and tortuous blood vessels of the fundus.

Table 6 showed the frequency of ocular findings in the study patients group, it revealed that the commonest detected finding is visual acuity disorders followed by conjunctiva calcification. 
Table 3. Comparison between patients group and their controls regarding the frequency and the degree of visual acuity disorders.

\begin{tabular}{|c|c|c|c|c|c|c|c|}
\hline \multicolumn{2}{|c|}{ Variable } & \multicolumn{2}{|c|}{$\begin{array}{c}\text { Control group } \\
\text { No. }=30\end{array}$} & \multicolumn{2}{|c|}{$\begin{array}{c}\text { Patients group } \\
\text { No. }=30\end{array}$} & \multicolumn{2}{|c|}{ Chi-square test } \\
\hline & & No. & $\%$ & No. & $\%$ & $\mathrm{X}^{2}$ & P-value \\
\hline \multirow{2}{*}{ V/A Rt } & Negative & 26 & $86.7 \%$ & 12 & $40.0 \%$ & \multirow{2}{*}{14.067} & \multirow{2}{*}{0.001} \\
\hline & Positive & 4 & $13.3 \%$ & 18 & $60.0 \%$ & & \\
\hline \multirow{2}{*}{ V/A Lt } & Negative & 26 & $86.7 \%$ & 8 & $26.7 \%$ & \multirow{2}{*}{21.991} & \multirow{2}{*}{0.001} \\
\hline & Positive & 4 & $13.3 \%$ & 22 & $73.3 \%$ & & \\
\hline \multirow{2}{*}{\multicolumn{2}{|c|}{ Degree of V/A R $t$}} & \multicolumn{2}{|c|}{$\begin{array}{c}\text { Mean } \pm \text { SD } \\
\text { No. }=30\end{array}$} & \multicolumn{2}{|c|}{$\begin{array}{c}\text { Mean } \pm \text { SD } \\
\text { No. }=30\end{array}$} & $\mathrm{t}$ & $P$-value \\
\hline & & & .07 & 0.2 & .34 & 4.102 & 0.001 \\
\hline \multicolumn{2}{|c|}{ Degree of V/A Lt } & \multicolumn{2}{|c|}{$0.03 \pm 0.07$} & \multicolumn{2}{|c|}{$0.29 \pm 0.30$} & 4.623 & 0.001 \\
\hline
\end{tabular}

V/A: visual acuity.

Table 4. Comparison between patients group and their controls regarding the frequency of eye symptoms (dry eye), anterior segment examination, fundus changes and retinal abnormalities.

\begin{tabular}{|c|c|c|c|c|c|c|c|}
\hline \multirow[t]{2}{*}{ Variable } & & \multicolumn{2}{|c|}{$\begin{array}{c}\text { Control } \\
\text { group }(n=30)\end{array}$} & \multicolumn{2}{|c|}{$\begin{array}{c}\text { Patients } \\
\text { group }(n=30)\end{array}$} & \multicolumn{2}{|c|}{ Chi-square test } \\
\hline & & No. & $\%$ & No. & $\%$ & $\mathrm{X}^{2}$ & P-value \\
\hline \multirow{2}{*}{ Dry eye } & No & 30 & $100.0 \%$ & 28 & $93.3 \%$ & \multirow{2}{*}{2.069} & \multirow{2}{*}{0.150} \\
\hline & Yes & 0 & $0.0 \%$ & 2 & $6.7 \%$ & & \\
\hline \multirow{2}{*}{ Eye lid abnormalities } & Negative & 30 & $100.0 \%$ & 27 & $90.0 \%$ & \multirow{2}{*}{3.158} & \multirow{2}{*}{0.076} \\
\hline & Positive & 0 & $0.0 \%$ & 3 & $10.0 \%$ & & \\
\hline \multirow[b]{2}{*}{ Conjunctiva abnormalities } & Negative & 28 & $93.3 \%$ & 19 & $63.3 \%$ & \multirow[b]{2}{*}{7.954} & \multirow[b]{2}{*}{0.005} \\
\hline & Positive & 2 & $6.7 \%$ & 11 & $36.7 \%$ & & \\
\hline \multirow{2}{*}{ - Conjunctiva calcification } & Negative & 30 & $100 \%$ & 26 & $86.7 \%$ & \multirow{2}{*}{4.286} & \multirow{2}{*}{0.038} \\
\hline & Positive & 0 & $0.0 \%$ & 4 & $13.3 \%$ & & \\
\hline \multirow[b]{2}{*}{ - Conjunctiva vacuoles } & Negative & 30 & $100.0 \%$ & 28 & $93.3 \%$ & \multirow[b]{2}{*}{2.069} & \multirow[b]{2}{*}{0.150} \\
\hline & Positive & 0 & $0.0 \%$ & 2 & $6.7 \%$ & & \\
\hline \multirow{2}{*}{ - Conjunctiva pigmentation } & Negative & 30 & $100.0 \%$ & 26 & $86.7 \%$ & \multirow{2}{*}{4.286} & \multirow{2}{*}{0.038} \\
\hline & Positive & 0 & $0.0 \%$ & 4 & $13.3 \%$ & & \\
\hline \multirow{2}{*}{ - Follicular conjunctivitis } & Negative & 28 & $93.3 \%$ & 29 & $96.7 \%$ & \multirow{2}{*}{0.351} & \multirow{2}{*}{0.554} \\
\hline & Positive & 2 & $6.7 \%$ & 1 & $3.3 \%$ & & \\
\hline \multirow{2}{*}{$\begin{array}{l}\text { Corneal abnormalities } \\
\cdot \quad \text { Corneal calcification }\end{array}$} & Negative & 30 & $100.0 \%$ & 25 & $83.3 \%$ & \multirow{2}{*}{5.455} & \multirow{2}{*}{0.020} \\
\hline & positive & 0 & $0.0 \%$ & 5 & $16.7 \%$ & & \\
\hline \multirow{2}{*}{ - Corneal vasculature } & Negative & 30 & $100.0 \%$ & 29 & $96.7 \%$ & \multirow{2}{*}{5.455} & \multirow{2}{*}{0.020} \\
\hline & Positive & 0 & $100.0 \%$ & 1 & $3.3 \%$ & & \\
\hline \multirow[b]{2}{*}{ Fundus changes } & Normal & 30 & $100.0 \%$ & 26 & $86.7 \%$ & & \\
\hline & Abnormal & 0 & $0.0 \%$ & 4 & $13.3 \%$ & 4.286 & 0.038 \\
\hline & Negative & 30 & $100.0 \%$ & 27 & $90 \%$ & & \\
\hline 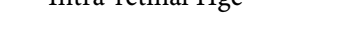 & Positive & 0 & $0.0 \%$ & 3 & $10 \%$ & & \\
\hline Myonic fundus & Negative & 30 & $100.0 \%$ & 29 & $96.7 \%$ & 2069 & 0150 \\
\hline & Positive & 0 & $0.0 \%$ & 1 & $3.3 \%$ & & \\
\hline
\end{tabular}


Table 5. The relation between tortuous ocular blood vessels with duration of hemodialysis and serum creatinine level in children on regular hemodialysis.

\begin{tabular}{cccccc}
\hline \multirow{2}{*}{ Variable } & & \multicolumn{2}{c}{ Tortuous vessels } & t & P \\
\cline { 3 - 4 } & & Negative & Positive & & \\
\hline Duration of hemodialysis (years) & Median (IQR) & $4(2-5)$ & $7(7-13)$ & $-2.628 \ddagger$ & $\mathbf{0 . 0 0 9}$ \\
Creatinine Level & Mean \pm SD & $7.80 \pm 1.95$ & $10.77 \pm 1.61$ & -2.533 & $\mathbf{0 . 0 1 7}$ \\
\hline
\end{tabular}

‡: Mann Whitney test. •: Independent t-test.

Table 6. Frequency of ocular findings in the study patients group.

\begin{tabular}{ccc}
\hline Variable & No (30) & $\%(100)$ \\
\hline V/A changes & 20 & $66.7 \%$ \\
Corneal calcification & 5 & $16.7 \%$ \\
Conjunctiva calcification & 4 & $13.3 \%$ \\
Fundus changes & 4 & $13.3 \%$ \\
Lens abnormalities & 2 & $6.7 \%$ \\
IOP changes & 2 & $6.7 \%$ \\
\hline
\end{tabular}

IOP :intraocular pressure.

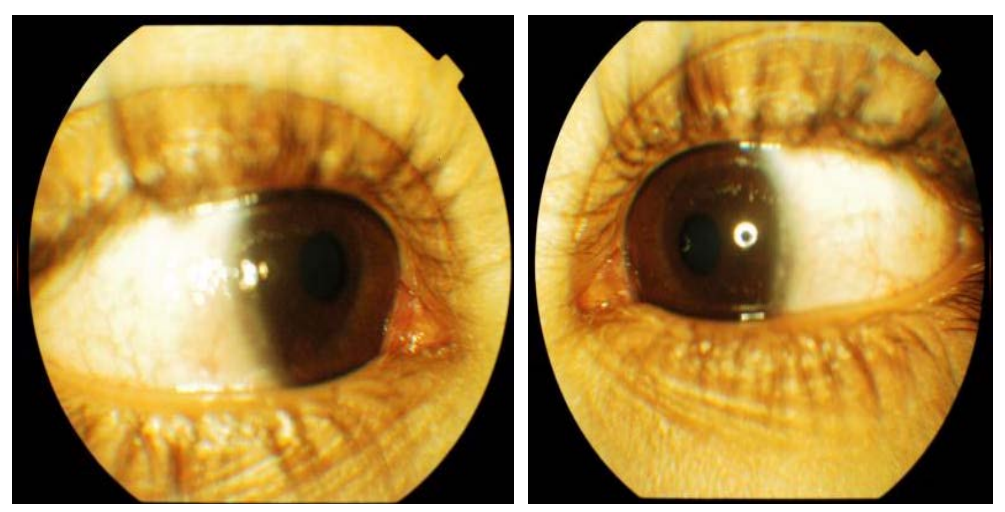

Figure 1. Corneal and conjunctival calcification of both eyes in one of the study patients group.

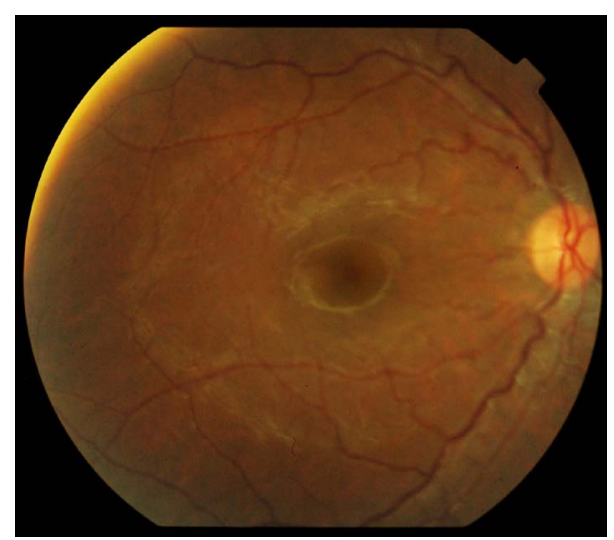

Figure 2. Retinal hemorrhage in one of the study patients group. 


\section{Discussion}

Several studies in adult population have reported a sudden and severe decrease in visual acuity in patients on hemodialysis [8], while studies that evaluate this issue in a pediatric population with ESRD are generally deficient.

In the present study we evaluated visual acuity disorders and the degree of visual acuity in a group of Egyptian children on regular hemodialysis in comparison to their healthy controls, it showed significant increase in visual acuity disorders in hemodialysis children with significant decrease in the degree of visual acuity in $60 \%, 73 \%$ in both right and left eye respectively in hemodialysis patients in comparison to $13.3 \%$ in either eyes among controls detected by Landolt's broken ring chart. Patients with CKD are more likely to suffer from visual impairment than without CKD [9].

Hemodialysis (HD) patients often complain of both acute and chronic vision changes. Decreased vision in CKD patients hampers daily activities, with increased incidence of falls and difficulty in performing personal tasks [10].

Acute changes could be secondary to changes in parameters during HD as rapid shifts of body fluid, abrupt changes of glycemic control and retraction of macular edema [8], but chronic changes most often result from eye disease secondary to the primary cause of renal insufficiency e.g. hypertension [5].

Visual acuity depends on the health of the cornea, lens, and retina, all of which are prone to change during HD [11].

This study showed that corneal and conjunctival calcification was reported in $16.7 \%, 13.3 \%$ respectively of the study patients group in comparison to zero\% in their controls. Common ocular surface findings in hemodialysis patients are corneal and conjunctival calcifications, which sometimes leads to red eye and squamous metaplasia [12], the calcific deposits have been shown histologically to be calcium phosphate. Precipitation of calcium salts is assumed to occur when serum concentrations of calcium and phosphate exceed solubility [13].

Uraemic toxins were reported to cause endothelial damage leading to polymegathism and pleomorphism in patients with chronic kidney disease [14] [15]. Anbar et al:; Akinic et al. [16] [17], reported that conjunctival and corneal deposits were detected in 3 (15.7\%) patients of children with CKD. However, ocular surface changes, mainly squamous metaplasia of the conjunctival epithelium, may develop in patients with ESRF undergoing hemodialysis in adult [18] [19] [20].

The present study revealed low mean values of $\mathrm{Wt}, \mathrm{Ht}$ and BMI $\mathrm{z}$ scores among CKD patients in comparison to healthy controls.; patients on chronic dialysis and especially children are malnourished, which reflects the state of vitamins and minerals deficiency which play a golden role in all organ functions including the eye [21].

This study showed that only 2 patients (6.7\%) have lens abnormalities, one patient had Lt posterior subcapsular opacity and the other had bilateral pseudophilic lens. Urea trapping in the lens causes chronic water accumulation within 
the lens, ultimately leading to an osmotic cataract, once patients are on chronic dialysis, intermittent fluxes of fluid into and out of the lens may also lead to chronic changes in the lens with cataract formation [22]. Also oxidative stress in CKD patients may lead to carbamylation of lens proteins, a process that has been suggested to cause cataract [23]. Akinic et al. [17] reported a similar finding.

Regarding the fundus of the eye examination, this study reported that, 4 patients (13.3\%) developed fundus abnormalities, 3 patients (10\%) had intraretinal Hge and only one patient (3.3\%) had myopic fundus, meanwhile the most detected retinal microvasculature abnormalities were congested vessels (33.3\%) then hyperemic disc (16.7\%) followed by attenuated arteries (13.3\%).

Generalized retinal arteriolar narrowing typically reflects permanent or persistent damage usually from atherosclerosis or longstanding hypertension [24]. The possible explanation for the retinopathy-kidney link might be: retinal microvascular abnormalities resulting from, hypertension, inflammation and other process may provide a common pathophysiologic link for the development and progression of CKD [25].

Gao et al. [25] reported that high prevalence of ocular fundus abnormalities in CKD patients, these data originate solely in adult patients.

The duration of hemodialysis and serum creatinine levels were the only related factor that seems to affect the blood vessels tortuosity among the study patients group. This was consistent with [17] who reported that the duration of the disease seems to be the major disease-related factor affecting ocular changes.

\section{Conclusion}

Eye and visual abnormalities are not uncommon in children on hemodialysis. So regular follow up and visual rehabilitation will be beneficial in these patients to improve their quality of life.

\section{Conflicts of Interest}

The authors declare no conflicts of interest regarding the publication of this paper.

\section{References}

[1] Delles, C. and Vanholder, R. (2017) Chronic Kidney Disease. Clinical Science, 131, 225-226. https://doi.org/10.1042/CS20160624

[2] Alaygut, D., Torun-Bayram, M., Soylu, A., Kasap, B., Turkman, M. and Kavukcu, S. (2013) Chronic Kidney Disease in an Adolescent with Hyperuricemia: Familial Juvenile Hyperuricemic Nephropathy. The Turkish Journal of Pediatrics, 55, 637-640.

[3] Nakata, M., Okada, Y., Kobata, H., Shigematsu, T., Reinach, P.S., Tomoyose, K. and Saika, S. (2014) Diabetes Mellitus Suppresses Hemodialysis-Induced Increases in Tear Fluid Secretion. BMC Research Notes, 7, 78.

https://doi.org/10.1186/1756-0500-7-78

[4] Aktaş, S., Sağdık, H.M., Aktaş, H., Gülcan, E., Tetikoğlu, M., Coşgun, S., Çalışkan, S. and Özcura, F. (2015) Tear Function in Patients with Chronic Renal Failure Un- 
dergoing Hemodialysis. Renal Failure, 37, 245-248.

https://doi.org/10.3109/0886022X.2014.982487

[5] Ghasemi, H., Afshar, R., Zerafatjou, N., et al. (2012) Impact of Hemodialysis on Visual Parameters in Patients with End-Stage Renal Disease. Iranian Journal of Kidney Diseases, 6, 457-463.

[6] KDIGO (2012) KDIGO Clinical Practice Guideline for Anemia in Chronic Kidney Disease. Kidney International Supplements, 2, 283-287.

[7] Kaiser, P.K. (2009) Prospective Evaluation of Visual Acuity Assessment: A Comparison of Snellen versus ETDRS Charts in Clinical Practice. Transactions of the American Ophthalmological Society, 107, 311-324.

[8] Stoffelns, B.M. and Richard, G. (2010) Is Buckle Surgery Still the State of the Art for Retinal Detachments Due to Retinal Dialysis? Journal of Pediatric Ophthalmology and Strabismus, 47, 281-287. https://doi.org/10.3928/01913913-20091019-10

[9] Wong, T.Y., Klein, R., Sharrett, A.R., Manolio, T.A., Hubbard, L.D., Marino, E.K., et al. (2003) The Prevalence and Risk Factors of Retinal Microvascular Abnormalities in Older Persons. Ophthalmology, 110, 658-666. https://doi.org/10.1016/S0161-6420(02)01931-0

[10] Dahal, P. and Gouli, S. (2014) Ocular Findings in the Chronic Renal Failure. Journal of College of Medical Sciences-Nepal, 10, 18-24. https://doi.org/10.3126/jcmsn.v10i2.12949

[11] Chelala, E., Dirani, A., Fadlallah, A., Slim, E., Abdelmassih, Y., Fakhoury, H., et al. (2015) Effect of Hemodialysis on Visual Acuity, Intraocular Pressure and Macular Thickness in Patients with Chronic Kidney Disease. Clinical Ophthalmology, 9, 109-114. https://doi.org/10.2147/OPTH.S74481

[12] Türkcü, F.M., Türkcü, G., Temiz, G., Yüksel, H., Taş, M. and Tunç, N. (2014) Ocular Surface Findings in Chronic Renal Failure European Journal of General Medicine, 11, 148-152. https://doi.org/10.15197/sabad.1.11.60

[13] Sun, W., Sun, M., Zhang, M., Liu, Y., Lin, X., Zhao, S. and Ma, L. (2015) Correlation between Conjunctival and Corneal Calcification and Cardiovascular Calcification in Patients Undergoing Maintenance Hemodialysis. Hemodialysis International, 19, 270-278. https://doi.org/10.1111/hdi.12236

[14] Diaz-Couchoud, P., Bordas, F., Garcia, J., Camps, E. and Carceller, A. (2001) Corneal Disease in Patients with Chronic Renal Insufficiency Undergoing Hemodialysis. Cornea, 20, 695-702. https://doi.org/10.1097/00003226-200110000-00005

[15] Oghuro, N., Matsuda, M. and Fukuda, M. (1999) Corneal Endothelial Changes in Patients with Chronic Renal Failure. American Journal of Ophthalmology, 128, 234-236. https://doi.org/10.1016/S0002-9394(99)00086-0

[16] Anbar, M., Ahmed, A.R.H., El-Mazary, A.-A.M. and Mahmoud, R.A. (2016) Ocular Surface Disorders in a Group of Egyptian Children with End Stage Renal Failure on Dialysis: A Cross-Sectional Study. Journal of Ophthalmology, 2016, Article ID: 4767819. https://doi.org/10.1155/2016/4767819

[17] Akinci, A., Cakar, N., Kara, N. and Uncu, N. (2009) Ocular Findings in Children with Chronic Renal Failure. Cornea, 28, 5-6. https://doi.org/10.1097/ICO.0b013e318181f9f0

[18] Vrabec, R., Vatavuk, Z., Pavlovi'c, D., Sesar, A., Cala, S., Mandić, K. and Bućan, K. (2005) Ocular Findings in Patients with Chronic Renal Failure Undergoing Haemodialysis. Collegium Antropologicum, 29, 95-98.

[19] Dursun, D., Demirhan, B., Oto, S. and Aydin, P. (2000) Impression Cytology of the 
Conjunctival Epithelium in Patients with Chronic Renal Failure. British Journal of Ophthalmology, 84, 1225-1227. https://doi.org/10.1136/bjo.84.11.1225

[20] Bakaris, S., Ozdemir, M., Isik, I.O., Buyukbese, M.A. and Ozdemir, G. (2005) Impression Cytology Changes and Corneoconjunctival Calcification in Patients with Chronic Renal Failure. Acta Cytologica, 49, 1-6. https://doi.org/10.1159/000326108

[21] Caffery, B. (1991) Influence of Diet on Tear Function. Optometry and Vision Science, 68, 58-72. https://doi.org/10.1097/00006324-199101000-00010

[22] Evans, R.D. and Rosner, M. (2005) Fellows' Forum: Ocular Abnormalities Associated with Advanced Kidney Disease and Hemodialysis. Seminars in Dialysis, 18, 252-257. https://doi.org/10.1111/j.1525-139X.2005.18322.x

[23] Klein, B.E.K., Knudtson, M.D., Brazy, P., et al. (2008) Cystatin C, Other Markers of Kidney Disease, and Incidence of Age-Related Cataract. Archives of Ophthalmology, 126, 1724-1730. https://doi.org/10.1001/archophthalmol.2008.502

[24] Ooi, Q.L., Tow, F.K., Deva, R., Alias, M.A., Kawasaki, R., Wong, T.Y., et al. (2011) The Systemic Microvasculature in Chronic Kidney Disease. Clinical Journal of the American Society of Nephrology, 6, 1872-1878. https://doi.org/10.2215/CJN.10291110

[25] Gao, B., Zhu, L., Pan, Y., Yang, S., Zhang, L. and Wang, H. (2011) Ocular Fundus Pathology and Chronic Kidney Disease in a Chinese Population. BMC Nephrology, 12, 62. https://doi.org/10.1186/1471-2369-12-62 